\title{
Percent Recovered Normalized by Body Mass Index
}

National Cancer Institute

\section{Source}

National Cancer Institute. Percent Recovered Normalized by Body Mass Index. NCI

Thesaurus. Code C92413.

The percentage of the dose that is recovered from the specimen type, from dosing to end of the current collection interval divided by the body mass index. 